\title{
CONTRATOS ADMINISTRATIVOS E POLITICAS PÚBLICAS: A ERA DO ESTADO CONTRATUALIZADO
}

\author{
ADMINISTRATIVE CONTRACTS AND PUBLIC POLICIES: \\ THE ERA OF THE CONTRACTED STATE
}

\begin{abstract}
Vivian Cristina Lima López Valle
Doutora e Mestre em Direito do Estado pela UFPR. Especialista em Direito Administrativo pelo IBEJ. Especialista em Contratação Pública pelo Cedipre - Universidade de Coimbra. Professora Titular de Direito Administrativo da PUCPR. Coordenadora do Curso de Direito da PUCPR. Coordenadora do Curso de Especialização em Licitações e Contratos da PUCPR. Diretora Acadêmica do Instituto Paranaense de Direito Administrativo. Advogada. ORCID: [orcid.org/0000-0002-5793-2912]. vivian@vivianvalle.com.br
\end{abstract}

\section{Luiz Felipe de Lima Rodelli}

Especialista em Licitações e Contratos Administrativos pela PUCPR. Membro da Comissão de Infraestrutura e Desenvolvimento Sustentável da OAB/PR. Graduado em Direito pela PUCPR. Advogado.

ORCID: [orcid.org/0000-0002-6666-8332].

luiz_rodelli@live.com

Recebido em: 05.05 .2021

Aprovado em: 10.06 .2021

DOI: [doi.org/10.48143/rdai.18.vcllc]

ÁREA DO DIRETTO: Administrativo

Resumo: 0 estudo analisa o novo ambiente de contratação adotado pelo Estado moderno, pelo qual a busca do melhor interesse público legitima que politicas públicas assistenciais à população sejam delegadas a particulares para a execução mais aperfeiçoada do serviço público, inaugurando um novo paradigma na atividade administrativa da contemporaneidade, visando 0 incremento qualitativo e quantitativo de demandas públicas. Assim, a atividade contratual do Estado não pode mais ser compreendida,

\begin{abstract}
The study analyzes the new contracting environment adopted by the modern State, whereby the search for the best public interest legitimizes that public assistance policies for the population be delegated to private individuals for the most improved execution of public service, inaugurating a new paradigm in administrative activity of contemporaneity, aiming at the qualitative and quantitative increase of public demands. Thus, the contractual activity of the State can no longer be understood, exclusively, as
\end{abstract}


exclusivamente, como mero instrumento para atendimento de necessidades administrativas ou tão somente como meio para a delegação do exercicio de atividades públicas para os particulares. É preciso considerá-la, também, como forma de satisfação de direitos e liberdades constitucionais. A peculiaridade aqui se faz na utilização de contratos administrativos duradouros, nomeadamente as concessões e permissões, cuja delegação comporta a transferência da execução de serviços, utilidades, tal como infraestrutura pública. Convém, portanto, cotejar a harmonia entre a segurança juridica e a mutabilidade contratual, inerente à gestão na prestação de serviços públicos e disponibilização de infraestrutura por meio de relações duradouras. Isso porque, quanto maior a autonomia na implementação de metodologias, maior será a capacidade de adaptaçăo do contratado.

Palavras-chave: Contratos administrativos Políticas públicas - Administração Pública - Parceria público-privada - Mutabilidade contratual. a mere instrument to meet administrative needs or only as a means for delegating the exercise of public activities to individuals. It must also be considered as a means of satisfying constitutional rights and freedoms. The peculiarity here is made in the use of long-lasting administrative contracts, namely the concessions and permissions, whose delegation includes the transfer of the execution of services, utilities, such as public infrastructure. Therefore, it is important to compare the harmony between legal certainty and contractual mutability, inherent to management in the provision of public services and provision of infrastructure through long-term relationships. This is because, the greater the autonomy in the implementation of methodologies, the greater the adaptability of the contractor.

KEYWords: Administrative contracts - Public policy - Public administration - Public-private partnership - Contractual mutability.

SUMÁRI0: 1. Considerações iniciais. 2. Concessões e os enfrentamentos do cotidiano. 3. Contratos administrativos e o Estado contratualizado. 3.1. Contextualização do ambiente de contratação pública no Brasil. 3.2. Contratualização da atividade administrativa na contemporaneidade e a tutela dos riscos na Lei 11.079/04. 3.2.1. A era das parcerias do Estadoe a contratualização administrativa. 3.2.2. 0 novo ambiente de contratualização em Parceria Público-Privada produzido pela Lei $11.079 / 04$ e sua responsabilidade ao Estado. 3.2.3. A mutabilidade contratual e tendência de revisão no cenário de longa duração. 3.3. Politicas públicas no Estado contratualizado. 3.3.1. O limite do investimento do Estado nos contratos firmados com o particular via concessão. 3.4. Controle judicial de politicas públicas contratualizadas e ativismo judicial - limites e possibilidades. 3.4.1. A licitude do Poder Judiciário impor à Administração Pública a obrigação de fazer conferida pela jurisprudência do STF. 3.4.2. A concretização de direitos sociais assegurados pelo Judiciário à voga da inércia do Estado. 3.4.3. 0 conhecimento técnico de previsão orçamentária na problemática de precedentes: impacto e dever moral. 4. Reflexão. 5. Considerações finais. 6 . Referências.

\section{CONSIDERAÇÕES INICIAIS}

No sistema brasileiro de contratação pública com entes particulares via concessão e permissão, admite-se três espécies de contratos, são eles a concessão comum, regulado pela Lei $8.987 / 95$, concessão patrocinada e concessão 
administrativa, ambas conferidas pela Lei 11.079/04, aplicando-se subsidiariamente os princípios e regras da Lei Geral de Licitações 8.666/93, sem prejuízo das demais legislações pertinentes à matéria.

Nessa perspectiva, o estudo analisa o novo ambiente de contratualização adotado pelo Estado, pelo qual a busca do melhor interesse público legitima que políticas públicas assistenciais à população sejam delegadas a particulares para a execução mais aperfeiçoada do serviço público, inaugurando um novo paradigma na atividade administrativa da contemporaneidade, visando o incremento qualitativo e quantitativo de demandas públicas.

Em outras palavras, a contratação pública traduz para o Estado novas formas de desenvolver finalidades públicas que, até então, seriam realizadas por outros meios tradicionais de ação estatal, que, por sua vez, ficariam a encargo da Administração Pública executar, permitindo sua concentração a outros setores específicos visando o bom funcionamento do Estado.

No entanto, a materialização de tais políticas instrumentalizadas por contratos administrativos de longa duração não permite a oposição de sua revisão a qualquer tempo e grau de execução, isto é, não há como estabelecer o diálogo entre a participação democrática e a pessoa prestadora, uma vez que o decurso do tempo na exploração da atividade provoca gradativamente a estabilização contratual do serviço prestado, de modo a adotar a mutabilidade contratual como recurso de revisão para não interromper e prejudicar a continuidade da função delegada.

Desse modo, a atividade jurisdicional se imiscui à administrativa para individualizar o procedimento contratado e garantir a prestação ampla do serviço público, com vistas a assegurar os direitos constitucionalmente garantidos dos quais são titulares os populares, o que ocorre por meio do exercício do ativismo judicial no controle dos atos administrativos.

Inserido nesse contexto, a problemática emerge com a arguição do momento exato no qual o Poder Judiciário deve intervir no mérito dos atos administrativos, uma vez inobservado o compromisso estatal em fornecer tal garantia, cuja decisão judicial vincula o Estado na obrigação de cumprimento da ordem emanada, sem haver, no entanto, qualquer conhecimento prévio técnico dos magistrados exigido na solução do litígio, quer seja orçamentário, quer seja funcional, proferindo, via de consequência, decisões guiadas pelo impacto social do dever moral.

\section{CONCESSÕES E OS ENFRENTAMENTOS DO COTIDIANO}

A Administração Pública desempenha função fundamental na coordenação e regulação da vida em sociedade, por intermédio da qual mantém suas balizas nos 
princípios administrativos esposados no texto constitucional, infralegal e, paulatinamente, na construção jurisprudencial dos Tribunais Superiores. Sobretudo, regra-se pelo princípio da supremacia do interesse público, eis que persegue a eficiência na gestão administrativa por meio da execução de atividades inerentes à sua finalidade.

Nessa conjectura, há tempos o Estado adota o modelo da atividade estatal baseada em contratos administrativos. Entretanto, apenas nos últimos anos a recorrente prática ganhou espaço nos setores da função pública, cuja habitualidade produziu a normalização e aceitação da descentralização na busca mais qualificada da prestação do serviço público.

Assim, por meio de contratos públicos de concessão, o Estado transfere a responsabilidade direta da prestação do serviço ao concessionário, ao mesmo tempo em que retém o controle das variáveis atinentes ao cumprimento dos mesmos, uma vez que neles se inserem elementos políticos, econômicos, jurídicos e sociais nos quais o Estado, inequivocamente, deve se fazer presente, regulando, bem como controlando, os direitos e obrigações dos prestadores, ao passo que garantindo e assegurando os direitos dos usuários cidadãos.

Ocorre que as concessões e permissões para a execução de políticas públicas já estão, notadamente, inseridas no contexto da vida de todos os indivíduos, na qual a interrupção do serviço público pode inviabilizar a convivência em determinados espaços urbanos, que em razão do alto grau de indispensabilidade, requerem condições próprias para satisfazerem as necessidades da coletividade.

Ora, a destinação da contratação de outras finalidades, para além do objeto específico do contrato, pode significar atender a função social do contrato público, haja vista a potencialização da produção de efeitos favoráveis para a estrutura administrativa estatal.

Em vista disso, partindo de tal premissa, visa a presente pesquisa analisar o regime jurídico dos contratos administrativos e suas peculiaridades quanto à estabilização de políticas públicas, bem assim analisar os aspectos da reforma do Estado e as possibilidades de novos paradigmas de contratação no âmbito da Administração Pública, no sentido de tornar verossímil o ativismo judicial, na medida em que as decisões proferidas moldam e direcionam os efeitos dos contratos aos seus destinatários.

\section{Contratos administrativos e o Estado contratualizado}

\subsection{Contextualização do ambiente de contratação pública no Brasil}

No atual cenário jurídico-político em que discussões sobre desenvolvimentos políticos e sociais são comumente recorrentes, o estudo aprofundado de 


\section{REFLEXÃO}

A busca do melhor interesse público legitima que políticas públicas assistenciais à população sejam delegadas à iniciativa privada para a execução mais aperfeiçoada do serviço público. Diante dessa premissa, um novo paradigma na atividade administrativa contratual se inicia, visando o incremento qualitativo e quantitativo de demandas públicas sociais.

Para o Estado, a parceria com o particular significa a realocação de investimentos em outros setores da Administração Pública, uma vez que o serviço agora delegado compete ao concessionário. Por sua vez, nessa ocasião, o concessionário legitimado detém a execução da atividade anteriormente genuína do Estado, sob sua administração. Isso traduz, à luz da natureza do modelo contratual pactuado, a prestação duradoura da atividade pública, garantindo a continuidade do serviço pela possibilidade de mutação dos contratos administrativos de longa duração, eis que alcançam a estabilização em razão do decurso do tempo.

Nesse passo, o Estado não busca mais impor a sua vontade pela coerção, mas sim discute em igualdade de condições com parceiros privados obter colaboração e atingir a finalidade administrativa de tutela do interesse público.

Assim, vê-se que um dos pontos de maior diferença entre os contratos tradicionais e os contratos de concessão é a divisão dos riscos da contratação. Enquanto o regime da Lei 8.666/93 imputa quase a totalidade dos riscos para a Administração Pública, as concessões partem da divisão de riscos entre as partes contratantes.

Dentro desse contexto, por vez a prestação do serviço público não atende satisfatoriamente à coletividade, de modo que resta ao cidadão usuário prejudicado buscar amparo no Poder Judiciário, por intermédio do qual, pelo ativismo judicial, intervém no mérito do ato administrativo para assegurar a amplitude do direito violado pelo Estado, agora transferido ao particular mediante a prática da contratualização administrativa de setores públicos.

\section{CONSIDERAÇÕES FINAIS}

Por todo exposto, para além da visão, ainda recorrente, do propósito da contratação pública sob uma perspectiva meramente instrumental, burocrática e estrita da economicidade, cuja finalidade se cinge à salvaguarda privativa da maior vantagem exclusivamente econômica, a contratação pública deve ser visualizada como uma ferramenta a serviço do cumprimento efetivo dos fins constitucionais estatais e das políticas necessárias à sua concretização, isto é, deve ser integrada à prossecução do melhor interesse público. 
Assim, a atividade contratual do Estado não pode mais ser compreendida exclusivamente como mero instrumento para atendimento de necessidades administrativas ou tão somente como meio para a delegação do exercício de atividades públicas para os particulares. É preciso considerá-la, também, como forma de satisfação de direitos e liberdades constitucionais.

A respeito, a contratualização dos entes federados passa a funcionar como elemento de orientação do mercado para o serviço mais qualificado ao usuário, destinatário do ato, que pode ser avaliado por meio do volume de demandas judiciais propostas em face do exercício insuficiente da prestação da atividade contratada, cuja interferência é comumente retratada na figura do ativismo judicial.

De fato, o Estado assume inescusável responsabilidade quanto à prestação precária do serviço, mas não exclusiva, compartilhando os riscos agora com o particular prestador, o que traz, por si, a dinamização da atividade estatal.

Posto isso, percebe-se que a regulação realizada pela mudança suscitada nos contratos administrativos é compatível com o ordenamento jurídico brasileiro.

Portanto, o direcionamento constitucional para a contratação administrativa não somente admite, mas também estimula regimes próprios, voltados à peculiaridade de cada relação que se pretenda estabelecer entre a Administração e o particular. Vai daí que, salvo o respeito às normas constitucionais gerais e delineadoras, é esperada a convivência entre regimes distintos de contratação, cada qual com sua específica regulamentação, sem prejuízo de compartilharem institutos e elementos comuns a todos.

A existência de elementos contratuais comuns aos regimes não invalida a tese de autonomia e distinção entre estes, mas apenas orienta cautela na maneira com a qual esses elementos vão ser interpretados e aplicados em cada um dos contratos. Por óbvio, o risco, a remuneração, a divisão obrigacional, entre outros, são temas comuns a qualquer contrato, mas não é isso suficiente para uniformizar o modo pelo qual estes serão considerados em cada avença, antes de serem estabilizados pelo decurso que o tempo provoca em suas ações.

É por tal motivo que o regime da concessão representa uma unidade voltada a determinado objetivo e construída a partir de determinadas características, moldadas às especificidades do vínculo entre a Administração e o particular em cada arranjo contratual.

Por fim, quanto aos materiais e métodos para o desenvolvimento do presente artigo, salutar é esclarecer a utilização das ricas fontes de pesquisa do direito administrativo para subsidiar adequadamente a produção científica, entre as quais destaca-se a contumaz preferência por artigos publicados em periódicos, cujo conteúdo deu integral suporte. 
Não obstante, a análise jurisprudencial dos tribunais superiores foi determinante para sustentar o posicionamento da possibilidade do controle judicial no mérito dos atos administrativos, eis que o novo modelo de contratualização administrativa é destinado à implementação de políticas públicas, tendo como destinatários dos atos os cidadãos usuários.

Na sequência, tendo em vista a demasiada vigência dos contratos administrativos celebrados para a prestação mais eficiente da atividade pública, especialmente sobre sua capacidade de mutabilidade, foram pesquisadas fontes bibliográficas a respeito de novos paradigmas na contratação no âmbito das concessões, posto ser uma realidade constante a modificação das exigências demandadas pela sociedade, as quais precisam sempre ser supridas.

\section{REFERÊNCIAS}

BREUS, Thiago Lima. A realização de finalidades acessórias, transversais e/ou horizontais na contratação pública contemporânea. Revista de Contratos Públicos - RCP, Belo Horizonte, ano 5, n. 8, p. 173-196, set./fev. 2016;

CÂMARA, Jacintho Arruda; NOHARA, Irene Patrícia. Tratado de direito administrativo. In: DI PIETRO, Maria Sylvia Zanella (Coord.). Licitações e contratos administrativos. São Paulo: Revista dos Tribunais, 2014. v. 6.

CHEVALLIER, Jacques. O Estado pós-moderno. Tradução de Marçal Justen Filho. Belo Horizonte: Fórum, 2009. (Coleção Fórum Brasil-França de Direito Público).

DI PIETRO, Maria Sylvia Zanella. Direito Administrativo. 17. ed. São Paulo: Atlas, 2004.

ESTORNINHO, Maria João. Curso de direito dos contratos públicos: por uma contratação pública sustentável. Coimbra: Almedina, 2013.

GARCIA, Flávio Amaral. A mutabilidade e incompletude na regulação por contrato e a função integrativa das Agências. Revista de Contratos Públicos-RCP, Belo Horizonte, ano 3, n. 5, p. 59-83, mar./ago. 2014.

GARCIA, Flávio Amaral; RIBEIRO, Leonardo Coelho. Licitações públicas sustentáveis. Revista de Direito Administrativo - RDA, Rio de Janeiro, v. 260, maio/ ago. 2012.

GONÇALVES, Pedro Costa. A regulação do mercado da contratação pública. Revista de Contratos Públicos - RCP, Belo Horizonte, ano 3, n. 3, p. 201-208, mar./ ago. 2013.

GONÇALVES, Pedro Costa. Gestão de contratos públicos em tempos de crise. In: GONÇALVES, Pedro Costa (Coord.). Estudos de Contratação Pública. Coimbra: Coimbra Editora, 2010, v. III. 
GUIMARÃES, Edgar; FRANCO, Caroline da Rocha. Controle das políticas públicas por meio das licitações. Revista Brasileira de Direito Público - RBDP, Belo Horizonte, ano 12, n. 46, p. 127-134, jul./set. 2014.

GROTTI, Dinorá Adelaide Musetti. A experiência brasileira nas concessões de serviço público. Interesse Público, v. 9, n. 42, 2007.

JUSTEN FILHO, Marçal. Comentários à Lei de Licitações e Contratos Administrativos. 16. ed. São Paulo: Revista dos Tribunais, 2014.

MOREIRA, Egon Bockmann; MILANO, Célio Lucas. Contratos públicos delongo prazo: a segurança jurídica advinda da certeza da mudança. Revista de Direito Público da Economia - RDPE, Belo Horizonte, ano 9, n. 34, p. 171-183, abr./ jun. 2011.

MOTTA, Carlos Pinto Coelho. Pontos polêmicos das parcerias público-privadas. Fórum de Contratação e Gestão Pública-FCGP, Belo Horizonte, ano 9, n. 102, p. 7-22, jun. 2010.

OLIVEIRA, G.H.J. A arbitragem e as parcerias público-privadas. In: SUNDFELD, Carlos Ari (Coord.). Parcerias público-privadas. São Paulo: Malheiros, 2005. p. 567-606.

PEREIRA JUNIOR, Jessé Torres; DOTTI, Marinês Restelatto. Alterações do contrato administrativo: releitura das normas de regência à luz do gerenciamento de riscos, em gestão pública comprometida com resultados. Fórum de Contratação e Gestão Pública-FCGP, Belo Horizonte, ano 8, n. 88, abr. 2009.

REIS, Luciano Elias. A regulação do Estado brasileiro e a contratualização administrativa. Fórum de Contratação e Gestão Pública - FCGP, Belo Horizonte, ano 16, n. 186, p. 33-40, ago. 2016.

RIBEIRO, Mauricio Portugal; PRADO, Lucas Navarro. Comentários à Lei de PPP Parceria Público Privada: fundamentos econômico-jurídicos. São Paulo, Malheiros, 2007.

SOUZA, Otavio Augusto Venturini de. O paradigma processual da atividade administrativa. Revista Brasileira de Estudos da Função Pública - RBEFP, Belo Horizonte, ano 4, n. 11, p. 55-93, maio/ago. 2015.

SUNDFELD, Carlos Ari. Guia jurídico das parcerias público-privadas. In: SUNDFELD, Carlos Ari (Coord.). Parcerias público-privadas. São Paulo: Malheiros, 2005. 